
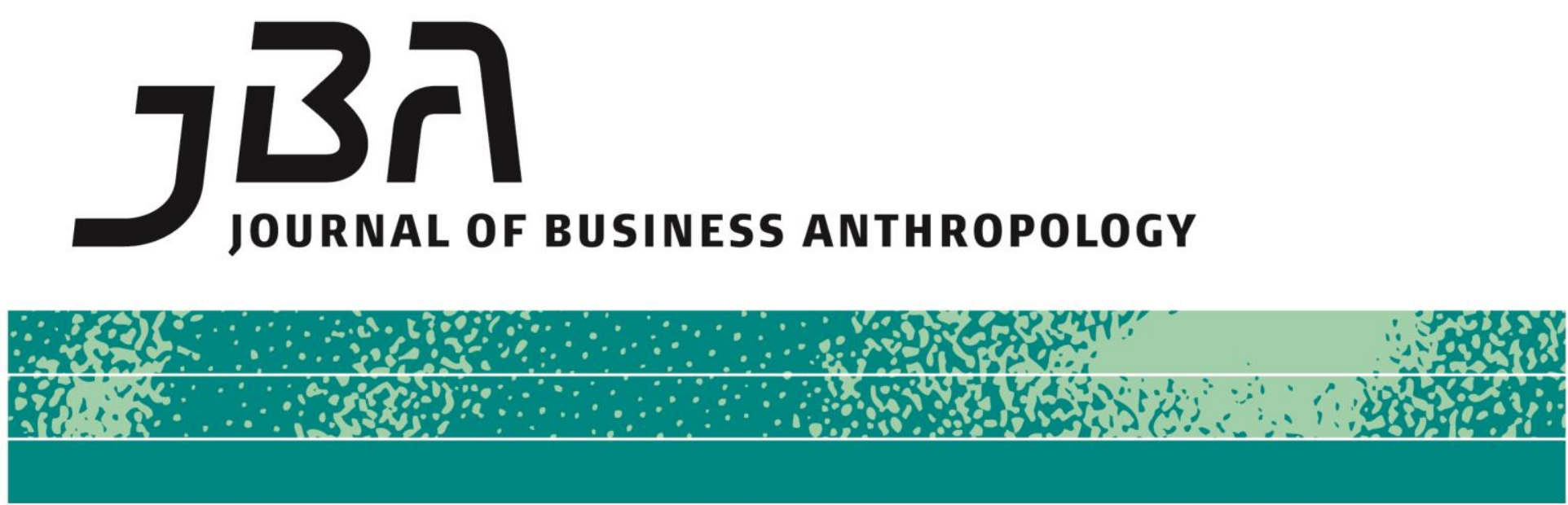

\title{
Essay
}

\section{The Phenomenology of Aging}

\author{
Michael Donovan
}

One could very well ask: why start an essay with such a big and potentially distancing word as phenomenology? My spell checker doesn't even like it, though I would hardly select this tool as an arbiter of lexical nuance. And, based on a recent lecture I attended in which a Media Studies professor drew, quite glibly I thought, on the phenomenology of religion to talk about the "embodied" experiences of playing games on his iPhone, it seems the word has achieved a certain populist intellectual fashionableness. This, too, is something I want to avoid.

However, I have chosen to stick with it for a number of reasons. Firstly to distinguish the topic from the physiology of aging, which is intensively studied and explored. I am not familiar with this literature-nor up till now have I had much of an appetite for it-but I think the subject will require at least a fleeting exposure as I continue writing, at least in referencing some links between the cognitive, the organic, and the experiential. It is, in fact, the experience(s) of aging that I want to examine, and the ways those experiences are shaped in and by contemporary America-shaped in the living, as a phenomenologist might express this. And this is why I did not simply title this essay "On Getting Older," or something of the sort. I want to assert a little analytic, or at least descriptive, distance in engaging the topic and, truth be told, a bit of psychic distance as well-although this is, at its core, nothing more or less
Page 1 of 9

JBA 2(1): 165-173 Spring 2015

(C) The Author(s) 2015 ISSN 2245-4217

www.cbs.dk/jba 
than a very personal essay.

The thought for this essay was planted during an elevator ride going down from my gym. Flush with the sociability that typically accompanies a good work out, I was telling Otto, a gym buddy standing next to me, about the growth spurts that my twins were experiencing. These rapid transformations in the size and appearance of my children are startling and a bit disconcerting. How could people you know so well, whose very personhood and relationship with you are fixed in some unexamined ways in their diminutive forms, turn in a flash into lanky giraffes or NFL running backs? How are these spurts, and the psychic turbulence they trigger, implicated in the knowing of one and other? Well, this is not elevator talk. So, I just made a remark about how "amazing" it was to witness such things when a woman standing right behind us piped up said: "There are aging spurts too."

Now this stuck me as a provocative and slightly subversive thing for a stranger on an elevator to say. But most of all it felt true. It captured some felt experience that I had not fully recognized or clearly examined. Aging spurts? Not some kind of a counter-balance to growth spurts on the biological ledger of life, but a way to frame the quick shifts in perspective that I have been experiencing. Did it make sense to think of these as "spurts" that disrupt and reframe my engagement with the world (sort of like what's been happening with my kids)? And how does this track with physical changes that I imagined the stranger in the elevator was actually referencing?

The elevator door opened and we all made a rather awkward exit. I remarked with cautious politeness that "yes, there must be aging spurts," though I was not sure at all what she, or I for that matter, really meant by that. But it seemed neither of us was inclined to pursue this subject on the street. As I started down the sidewalk, I decided to screw up the courage to examine the idea. The fact that it was an idea or, more engagingly, a set of propositions, is what provided the spark. Who wants to devote the time, even over a short walk, to taking stock of one's mortality? But entertaining a proposition is another story. It captured my imagination, both as an assertion that could be interrogated and potentially as a way of framing, and thus of making sense of, some of my own experiences.

My approach to exploring the idea of aging spurts was to apply my own experiences and see how well they fit. Regardless of how analytically flimsy this seems, it might make my experiences more coherent, or at least cogent, to me. After all, it is the subjective that I wish to plumb, which-I think we all can agree-is a prerequisite for empathy.

Here are the propositions first articulated on my walk home:

- P1. There are aging spurts; 
- P1.1 There are (some) aging spurts that are not directly tied with physiological processes associated with aging;

- P1.2 These kinds of experiences of aging involve a rapid shift in perspective, much like I experience when witnessing my children's growth spurts.

These last two propositions point to the experiential dimensions of aging that lie somewhere between the physiological and the cultural. They speak to the phenomenological assertion that aging is shaped in the living of it. They posit that aging is a set of interior or subjective experiences, as well as a set of biological processes. That's clear enough, and seems consonant with common usage: for example the expression, "feeling your age," as in the phrase "All of a sudden she was feeling her age." But this opened up another door, and I quickly had to expand my propositions. For what could "feeling your age" (or acting your age) mean outside of a metaphoric or cultural context? Aging is also a relational process-not some atomized experience-even though in present day America it may trigger a sense of anomie or isolation. We construct, and in some measure negotiate, the meanings of aging with others and with the world around us.

So I added the following:

- P1.3 Even physiological changes that are attributable to the aging process, things like hearing loss, vision loss, word loss (aging seems to be a litany of losing things), are signifiers of aging that, independently of their etiology and physical effects, have potent social meanings.

Could this "shaping" of our experience of aging be understood, at least in part, by something called aging spurts-rapid shifts in perspective that change one's engagement with the world? My set of propositions gave me a very wide berth to examine this question, even as the language itself pointed me towards some semantically fuzzy terrain. I was not interested in measuring aging spurts, like I might take a tape measure or a scale to measure my kids' growing spurts. (Such data about aging might be traceable, but I'm not especially keen on examining it). But I was intrigued by the idea of triggers. Spurts have to have some kind of onset. And my propositions lavishly provide space to explore these phenomena since aging triggers, according to my definitions, need not be physiological: even if they are rooted in the physiological, they also have relatively autonomous social meanings.

Medical practitioners do recognize this dynamic in clinical terms. An older patient breaks a bone, loses their mobility, becomes dependent on others (family, friends, caretakers), suffers from depression and possibly cognitive impairment. This rapid cascade of events changes a person's status and engagement with the world - their autonomy is compromised, and with it comes a kind of cultural reclassification into the ranks of the elderly. Perhaps this is what my elevator mate meant by 
aging spurts.

Sophisticated approaches to managing a case like this are crossdisciplinary. They might involve orthopedics, physical and occupational therapy, psychiatry, pharmacology, psychology, social work, even family counseling. And, theoretically at least, they could draw on fields as diverse as architecture, sociology, public health, law, and anthropology, to name a few. Welcome to the burgeoning world of gerontology, which moves in some fascinating ways between the biological, the behavioral, the psychological, the sociological, the cultural, the geographic, and the political.

But where does the experiential fit in all this? Of course, it has roots and tendrils in all these domains. The challenge, I felt, was to move past the indisputable but almost trite assertion that aging is "culturally mediated," towards some understanding of the substrate of those experiences (I think it is more accurate here to think in the plural) that draws on social meanings, signs and symbols, and that is also grounded in organic, biological changes that are part of getting older.

I am asking that we shift our gaze from examining and deconstructing (scrutinizing) the medical and cultural narratives of aging and look instead at how these narratives are lived and contested. Let's think about how they are encountered in particular life moments and become catalysts for change. Perhaps there are gerontologists who study such things. My interest was not to stumble into new fields, but once again to interrogate my own experiences. Let me give some examples.

I am a 61 year old father of eight year old twins, and so firmly fall into a cohort of "older dads" that have at least a chimeric demographic footprint in my native Brooklyn. I have (wincingly) heard or seen this cohort referred to as "those gray haired dads of Brooklyn" somewhere in print or on the radio, so I guess "we" share some dubious sociological identity. I myself have had white hair for at least a decade and within the last year or so increasingly white eyebrows. These are indisputably signifiers, as well as physical expressions, of aging, though they did not feel that way till recently.

Relying on memory to reconstruct shifts in my subjective experience of aging is treacherous, since the process I am tracing was actually a stutter step, with glimpses of an older me flashing into focus. But I can say confidently that I did not see myself as an "older guy," regardless of my chronological age and appearance, until quite recently. All this changed when I started regularly taking my kids to school.

Entering the courtyard at PS 295 where I drop my kids for elementary school, I find it absurd to assert that "age is just a number". While there are expressions of absurdism that I admire, even aspire to, they do not fit within the morally staunch ethos that prevails among third graders, especially regarding grownups. I can only imagine such a chirpy 
call to arms carrying any weight in a (homogeneous) enclave like Delray Beach, Florida. But at drop off time, where the mean age of adults, (teachers, parents, baby sitters) is probably around 32, I fall into an illdefined, but markedly separate, social and symbolic space.

Well, not altogether. Many of the Hispanic parents, their kids, and the occasional baby-sitting abuela confidently assume that I am "the grandfather." But to the other Brooklyn moms and dads, members of the "creative class" (like my wife and myself), I am somewhat of a liminal character-like the trickster of anthropological lore, betwixt and between. I could be their dad. Perhaps I even look like their dad; yet there I am, a member of their social club as it were: one of parents.

This in-betweeness can be unsettling. I occasionally catch this in the darting eyes of a parent who, I imagine, is at least subliminally in tune with the dangerous ambiguities of the situation. Of course this may be my imagination gone amok: what sorts of dangerous ambiguities are we talking about? Yet there is undoubtedly some jarring ripple that my presence can make in the normative order of things. Typically, I can smooth the waters with a smile or a greeting. There are even a few fellow parents-dads mostly-with whom I have built casual friendships.

It is here, engaging in those "bonding" moments with fellow parents, where the idea of aging spurts seems to make sense. Questions of fluency and idiom arise and these can have a jostling effect. It is not that the chasm of generational experience is too, too wide, but really (and quite meaningfully to me) the tonalities, accents, ironies are different. This goes beyond the standard references to pop culture-the Decembrists, rather that the Doors, stretching to identify some pop middle ground in Elvis Costello or the Ramones. Is there any band out there that is even kind of like the Fugs or Captain Beefheart? It runs right up against one's most tacit and unselfconscious sense of self. Hence the jostling effect.

Indexing one's generational identity though music is cliché and fundamentally faulty. My dad liked Duke Ellington and Gustav Mahler; my mom liked Ella Fitzgerald and Odetta; they both liked the Beatles, or at least tolerated Abbey Road on the high fi, and I grew up carrying all those musical notes into early adulthood. So I imagine fellow PS 295 parents have their own epoch-crossing song books. There is in fact lots territory that we share and lots to learn from each other. There's the topical stuff-like cross cutting experiences of parenting that bridge generational lines, cooperative projects for the school, strategies for pursuing our work, and being there for the kids. There are movies, the Nets in their new Brooklyn stadium, happy hour with tacos at Chavela's, an African pop performer at a local bar with the Wesleyan girls swaying up front like Senegalese villagers. The challenge for me is always one of translation.

It's back to the idioms. Yes, the notes, the accents, tonalities, ironies, 
and such. In some ways you can look at these as aesthetic differences-different tropes and modes of expression, different filters-that can become conspicuous in inter-generational exchange or chatter. I hesitate about how much of this to assign to my personality or to generational differences. And I am reluctant to feed the uncritical reification of "generations" advanced by marketers, pollsters, advertisers, journalists and pop sociologists-those ethnographers of "Millennials", the current "creators" and "curators" of pop culture, along with Gen Y, Gen C, Gen X, and the "early" and "late" Baby Boomers-who have created, and with astonishing success persuaded us to embrace, the existence of separate tribes cut by fiat from the sweep of recent history. One can't help but wonder (really?) how different it was to be in your twenties during the 70s, 80s, 90s, and 00s when, supposedly, the distinctive zeitgeists of each generation emerged. For the main I would say: Plus ça change; plus c'est la même chose. Throwing down the French always adds a bit of (faux) one-upmanship.

However, generational notes do pierce the air-most definitely traveling in both directions. To the discrete, Facebook weaned, moms and dads I rub elbows with, I must seem ham-fisted in my approach to discussions of school policy and the ultra-local politics of Brooklyn public education. Schooled in the style of the Merry Pranksters, my ironies tend to be broad, my language ribald. And theirs tends to be tuned to wider distribution: specifically, I think, to the semiotic field of social media. So much remains restrained, subtly or variably expressed, implicit. To me, this blending or merging of the virtual and real worlds (a spatio-temporal distinction that some who study Millennials scorn), and with it the close management of multiple selves, is extremely foreign-a mare's nest of the professional and the social, the intimate and the distant, the old and the new. These contrasting representations and experiences of self do not exactly create a sense of "otherness" between us (after all, we do exchange children for sleep-overs), but they do serve as subtle but profound markers of difference-that jostling shift in perspective that I have identified as an aging spurt. Like a man wondering what is happening to his spurting children, I ask what is happening to my "self." All of a sudden, in that potently theatrical space of the school courtyard, I feel my age.

Feeling one's age. This could be read as a story of life passages, of reconciliation with a shift in "life stage." Anthropologically speaking, it could be cast as an illustration of transition, from a condition of "liminality," being neither fish nor fowl, towards assuming a new social identity. It could be a story of self-examination and, at least partially, fulfillment. And this, at least partially, is the case. But, looking around at a larger social canvas, I find that there are some deep cracks in this narrative and underlying ideas about the order of things that support it. For my generation, or (eschewing the tribal connotations) for many folk my age, "feeling one's age" is anything but settled. There is no new, or 
"next" modal state we are comfortably, or resentfully for that matter, moving into; no normatively defined next "stage" (a paradigm shift that is likely to play havoc with the schemas of developmental psychologists). "We" are working out new ideas about what aging means and reinterpreting age-old experiences of what aging is, what it looks and feels like. Remember, aging is a relational process; its meanings are, at least in cultural terms, "to be determined" (viz. negotiated) in the "lived" world. The very fact that I am part of a cohort of dads who are both older guys and young fathers (in the life course sense that we have young kids) captures something of this. Perhaps, in these turbulent times, it is wise to hold on to our ambiguous, liminal status: to play the trickster for a while.

But to what end? Playing the trickster can be a tiresome thing. Victor Turner, an influential anthropologist of the mid-twentieth century, devoted substantial effort to symbolically unpacking "rites of passage," those rituals and ceremonies observable in all human societies-funerals, weddings, christenings, initiation ceremonies, bigger communal festivals such as coronations, or Lenten passages like Mardi Gras-that work to move us, symbolically and experientially, from one state of being to another. He was particularly interested in those in-between moments and spaces in the ritual process, when we play with (and so make visible and explicit) the symbols and metaphors of the social order or "structure." So, for example, during the saturnalia of Mardi Gras, the poor parody the rich, sexual mores are upended, gender and racial identities get mashed up. And, at least before the whole thing was Disneyfied, this in-between time in the Christian ritual calendar provided dramatic space in which our tacit understandings of the social order-class hierarchy, gender, racial, ethnic, local and sexual identities-were brightly scored, visible, and so accessible to ludic interpretation.

In his early work, Turner focused on the ways that these liminal moments revitalize and essentially sustain "structure" (hierarchies, identities, the social order). Once the shenanigans have passed, successions are managed, the dead are no longer with us, young boys have become men, maidens wives, the resurrection is (once again) behind us, the existing social order is restored with new gusto. The king is dead... Long live the king. Perhaps sensitive to critiques that his work was "ahistorical," caught in a kind of monotonic cyclical time where existing social forms are scrambled only to be reproduced, he came in his later writings to focus more explicitly on the disruptive and creative possibilities of such liminal moments. Liminality, he saw, offered the possibility of generating new metaphors for social life, of reframing existing forms. He called this culturally creative potential (somewhat awkwardly) "antistructure."

In this sense, I think, liminality becomes an interesting paradigm for examining "my" generation's ambiguous experiences of aging. Not without a certain irony, advances in the biological sciences are upending 
our normative expectations of generational hierarchy and succession-our tacit understandings of the social order that are so deeply rooted in organic (cultural) metaphors of life giving way to disease, death and renewal... Bury me under the old oak tree. In contretemps, the Ponce de Leon-like prophets of nanotechnology and genetic engineering draw their organizing metaphors from information science and "computers." Think in terms of "exponential progression"-the model applied to describe advances in computing, miniaturization and more recently our understanding of the human genome. Where go the ancient organic metaphors of degeneration and rebirth, and those structural models of social order based on cyclical time, in the face of these ever upward trending graphs of growth and capability? We are told that, if we can hang in for another ten or twenty years, hold off the corrosive effects of free radicals and inflammation (with our antioxidants), keep our weight in check, get out dancing, and do the daily crossword puzzle, we can last another 70 years after that, with the help of sundry molecular sized "bots" on patrol in our bodies. So, are we old at 60 or 70 ?

Well, yes and no. Bracketing for a moment class, genetics, and other vagaries of chance, from a medical standpoint some of us are and some of us aren't. Similarly, in many other domains-work, parenting, athletics, sexuality-our experiences, and yes, our cultural understandings of aging, are in play. Back to Victor Turner and his observations about the disruptive or culturally creative possibilities of the trickster figure, the one who stands some "place" (symbolically, structurally, imaginatively, experientially) in contemporary American life that is betwixt and between. We are back in the school courtyard at PS 295.

We have the opportunity, one could say special chance (and hasn't "our" generation always thought of itself as special), of offering new metaphors for understanding and giving shape to our experiences of aging. This new phenomenology of aging will happen largely, and (one can hope) most productively, in conversations with others who are younger than us: our children, and our children's children. Regardless of the potentially subversive power of "bots" in remaking the course of human biology, new understandings and experiences of aging will come from intergenerational conversations, and from a deep historical sense of attachment to and caring for those who are our children. And parenthetically, they are growing up with bots around every corner and deeply embedded in their imaginations. Perhaps some of these bots will be their aging parents. 
Michael Donovan holds and Ph.D. in Anthropology from New York University and works for Partner Practica Group LLC in New York, where he specializes in strategy consulting, marketing communications, branding, public policy and innovation. He has had the good fortune to bring his skills and experience as an anthropologist to an incredibly diverse set of projects. His work, which typically provides a fresh look at the cultural spaces inhabited by categories, brands, products and services, has yielded notable successes in new product development, retail design, portfolio management, audience development, messaging and strategic planning. He may be reached at

mdonovan@practicagroup.com 